\title{
Factors Associated With Sudden Death of Individuals Requiring Restraint for Excited Delirium
}

\author{
SAMUEL J. STRATTON, MD, MPH,${ }^{\star \dagger}$ CHRISTOPHER ROGERS, MD, ${ }^{\ddagger}$ \\ KAREN BRICKETT, RN, MSN, ${ }^{\S}$ AND GINGER GRUZINSKI, RN, BSN ${ }^{\dagger}$
}

The purpose of this article is to identify and rank factors associated with sudden death of individuals requiring restraint for excited delirium. Eighteen cases of such deaths witnessed by emergency medical service (EMS) personnel are reported. The 18 cases reported were restrained with the wrists and ankles bound and attached behind the back. This restraint technique was also used for all 196 surviving excited delirium victims encountered during the study period. Unique to these data is a description of the initial cardiopulmonary arrest rhythm in $72 \%$ of the sudden death cases. Associated with all sudden death cases was struggle by the victim with forced restraint and cessation of struggling with labored or agonal breathing immediately before cardiopulmonary arrest. Also associated was stimulant drug use $(78 \%)$, chronic disease $(56 \%)$, and obesity $(56 \%)$. The primary cardiac arrest rhythm of ventricular tachycardia was found in 1 of 13 victims with confirmed initial cardiac rhythms, with none found in ventricular fibrillation. Our findings indicate that unexpected sudden death when excited delirium victims are restrained in the out-of-hospital setting is not infrequent and can be associated with multiple predictable but usually uncontrollable factors. (Am J Emerg Med 2001;19:187-191. Copyright $\odot 2001$ by W.B. Saunders Company)

During the past 2 decades, there have been reports of sudden, unexpected death of individuals suffering extreme agitation or "excited delirium" immediately after being physically restrained. Most often these individuals are restrained with the wrists and ankles bound and all 4 extremities attached securely behind the back. ${ }^{1-4}$ Terms used to refer to this restraint procedure include hobble restraint, total appendage restraint procedure (TARP), and hog-tying. Many factors including positional asphyxia secondary to restraint technique, drug toxicity, obesity, ethnicity, and underlying heart disease with terminal cardiac rhythms have been proposed as contributory to sudden death while restrained for excited delirium. ${ }^{5,6}$ Most controversy concerning these unexpected deaths has centered on the theory of positional or restraint asphyxia as a primary contributing factor. ${ }^{1-4,}$, 7-11

From the *Harbor-UCLA Medical Center, Torrance, CA; † Los Angeles County Emergency Medical Services Agency, Los Angeles, $\mathrm{CA} ; \ddagger$ Department of the Coroner, County of Los Angeles, Los Angeles, CA; and the $\S$ California Department of Health Services, Sacramento, CA.

Manuscript received July 4, 2000, returned August 18, 2000, revision received October 20, 2000, accepted November 7, 2000.

Address reprint requests to Samuel J. Stratton, MD, MPH, Harbor-UCLA Medical Center - Box \# 21, 1000 West Carson Street, Torrance, CA 90509-2910. E-mail: stratton@emedharbor.edu

Key Words: Excited delirium, emergency medical services, physical restraint, sudden death, positional asphyxia.

Copyright (C) 2001 by W.B. Saunders Company

0735-6757/01/1903-0003\$35.00/0

doi:10.1053/ajem.2001.22665
Presented in this article is a consecutive case series of 18 excited delirium sudden deaths after struggle and physical restraint. In comparison with previous published data is that all reported cases were cardiopulmonary arrests witnessed by emergency medical service (EMS) paramedics and for $13(72 \%)$ of the cases, the initial cardiac rhythm at the time of paramedic assessment is described. The purpose of this article is to identify and rank factors associated with sudden death of individuals requiring restraint for excited delirium.

\section{METHODS}

Case series data were obtained by retrospective review of the records of the Los Angeles County EMS Agency patient encounter database and records from the Los Angeles County Coroner's Office. The study period was from December 1992 to December 1998. Cases of excited delirium with respiratory or cardiac arrest were entered onto the study if EMS paramedics witnessed the arrest at the scene. Excluded were cases for which there was an obvious cause of death identified by autopsy or those in which the victim sustained cardiac arrest before EMS arrival. Data were collected and confirmed as cases occurred, but a 1-year delay was observed for initiation of study analysis to avoid conflict with legal fact finding in cases being litigated.

Before initiation of data collection, EMS personnel were instructed that for restrained individuals they were to document mental responsiveness, method of restraint, use of prone versus lateral position, respiratory rate and quality of breathing, initial cardiac rhythm, heart rate, description of victim resistance at scene, witnessed or reported use of choke-hold, taser, or capsicum (pepper) spray, and if appropriate, site of cardiac or respiratory arrest. Midway through the data collection period, during 1996, collection of the data elements were again emphasized to personnel during training sessions on proper restraint techniques in the field. Data for this article were collected from original field reports and a separate data collection instrument was not used. Data that were not recorded on initial field reports was obtained on an ongoing basis by structured telephone interview of involved EMS field personnel. Data collected from Coroner's investigation reports included age, gender, weight, height, heart weight, evidence for use of chokehold, taser, or capsicum spray, evidence of injury, vitreous fluid glucose, and comprehensive toxicological tests for both legal and illegal drugs. Evidence of other disease states or past injuries was also collected from Coroner's autopsy reports.

Exact time delays in determining cardiac rhythm on arrival of EMS personnel to the scene was not available. 
Standard EMS procedure for cardiopulmonary arrest was for one paramedic to immediately apply quick-look paddles or patches to determine if ventricular fibrillation was present while the second paramedic managed the airway (all responding teams consisted of two paramedics). In this series, delay occurred in assessment of cardiac rhythm because of the time required to release restraints and allow placement of paddles or patches. In telephone debriefing sessions of EMS personnel these delays were estimated to vary between 30 to 190 seconds.

Data were entered into a standard relational database (Microsoft Access 97, Microsoft Corp., Redmond, WA) and descriptive statistics calculated using SPSS Base 9.0 statistical software (SPSS Inc., Chicago, IL). Descriptive statistics included calculation of $95 \%$ confidence intervals.

The study proposal and methods were reviewed and approved by the first author's university affiliated institutional review board and by the Coroner's Office Research Review Committee.

\section{RESULTS}

During the period of December 1992 to December 1998, there were 20 cases of excited delirium death associated with struggle and restraint that were witnessed by EMS personnel. All sudden death victims in the series had been hobble restrained. The total number of persons with excited delirium who were restrained during the study period is not known because restrained excited delirium victims are often taken directly by law enforcement to hospital emergency departments or custody centers without calling for EMS assistance. Local policies do not allow EMS use of hobble restraint procedures and during the study period it was noted that law enforcement personnel placed all cases reported in this article into hobble-type restraints. Toward the end of the data collection period, there was a decline in EMS responses to restrained excited delirium victims. The average annual number of EMS responses during the study period was 549,000 , with $35 \%$ of the total calls considered paramedic level responses. From 1993 through 1996 there was an annual average of 196,255 advanced life support (paramedic level) EMS calls within the study population. During 1993 to 1996, the use of restraints for excited delirium was documented an average of 47 times per year by EMS personnel and an average of 5 (11\% of those restrained) were witnessed, unexpected sudden deaths. In 1997, there were 186,425 advanced life support responses within the study population. During 1997, there were 21 reported responses to persons with agitation in which restraints were used, with $3(14.3 \%)$ suffering cardiopulmonary arrest. In 1998 , there were 206,124 advanced life support responses in the population, with response to 7 restrained excited delirium cases of which none had cardiopulmonary arrest.

Of the 216 restrained excited delirium victims encountered during the study, all had been restrained in some form of hobble restraint, either loosely (TARP) or tightly (hogtied). The TARP technique was used almost exclusively (in $91 \%$ of those encountered) after 1996. Theoretically, prone positioning as opposed to lateral positioning is considered an important component for potential positional asphyxia while hobble restrained. ${ }^{1-8,} 10$ Of the 216 hobble restrained individuals encountered by EMS personnel during the study period, $81 \%$ were initially found in prone position on arrival of EMS and $9 \%$ in a lateral position, with positioning not determined in $10 \%$. None of those who suffered sudden death while hobble restrained were found in a lateral position and therefore, calculation of a relative risk ratio for unexpected death while in prone position was not possible. Although all sudden death victims were found prone, almost all of those who did not suffer death while restrained were also in prone position on arrival of EMS. Therefore, our data do not allow for determination of how strong an association there is with prone positioning and sudden death while hobble restrained.

Of the 20 EMS witnessed restrained, excited delirium sudden deaths identified for study, 2 were excluded from the case series, one because he was found to have ligature marks and contusions of the anterior neck and the second because the victim was found to have a significant pulmonary thromboembolism. The physical characteristics of the study population are described in Table 1. For this study, body mass index (BMI) was calculated using the formula, BMI = weight (kilograms) divided by height (meters) squared. Ideal BMI is considered to be between 20 to 25 , preobese to be between 25 and 30 , and obese greater than $30 . .^{12}$ Heart weight at autopsy is also reported with normal range for the study population considered being $350+/-93$ grams. ${ }^{13}$ As shown in Table 1, the distribution of cases was equal among African American, Hispanic, and Caucasian ethnic groups. One female victim was represented in the group. Table 2 lists the physical findings noted on initial assessment by EMS personnel. Cardiac rhythm is only reported when the field rhythm was confirmed by physician review of a computer timed field rhythm strip recording or by confirmation by radio telemetry transmission to an EMS medical control base hospital. Data for confirmed initial cardiac rhythm

TABLE 1. Physical Characteristics of Study Population

\begin{tabular}{ccccccc}
\hline Patient & Age & $\begin{array}{c}\text { Ethnic } \\
\text { Group }\end{array}$ & $\begin{array}{c}\text { Weight } \\
(\mathrm{kg})\end{array}$ & $\begin{array}{c}\text { Height } \\
(\mathrm{cm})\end{array}$ & BMI & $\begin{array}{c}\text { Heart Wt } \\
(\mathrm{gm})\end{array}$ \\
\hline 1 & 35 & HS & 87 & 170 & 30 & 470 \\
2 & 40 & AA & 113 & 180 & 35 & 450 \\
3 & 37 & AA & 114 & 185 & 33 & 480 \\
4 & 35 & AA & 72 & 168 & 26 & 340 \\
5 & 30 & CA & 70 & 168 & 25 & 350 \\
6 & 25 & HS & 99 & 178 & 31 & 410 \\
7 & 24 & HS & 76 & 165 & 28 & 350 \\
8 & 25 & CA & 78 & 175 & 25 & 375 \\
9 & 31 & HS & 77 & 185 & 23 & 380 \\
10 & 32 & CA & 124 & 190 & 34 & 470 \\
11 & 25 & CA & 80 & 183 & 24 & 380 \\
12 & 43 & CA & 126 & 168 & 45 & 650 \\
$13^{*}$ & 29 & AA & 84 & 160 & 33 & 330 \\
14 & 30 & HS & 74 & 165 & 27 & 410 \\
15 & 37 & CA & 95 & 178 & 26 & 440 \\
16 & 44 & AA & 88 & 178 & 28 & 500 \\
17 & 28 & HS & 89 & 170 & 31 & 380 \\
18 & 28 & AA & 98 & 180 & 30 & 370 \\
Mean & 32.1 & & 91 & 175 & 30 & 419 \\
$(95 \%$ Cl) & $(29,35)$ & & $(82,100)$ & $(172,179)$ & $(27,32)$ & $(380,457)$ \\
\hline
\end{tabular}

Abbreviations: AA, African American; HS, Hispanic; CA, Caucasian. * Only female in study group. 
TABLE 2. Physical Findings on Initial EMS Contact in the Field

\begin{tabular}{rrlll}
\hline Patient & Resp Rate (min) & Response & Cardiac Rhythm & Heart Rate (min) \\
\hline 1 & Agonal & Obtunded & VT & NA \\
Pepper
\end{tabular}

Abbreviations: VT, ventricular tachycardia; ASY, asystole; AGO, slow, wide complex (agonal); JUNCT, junctional; ST, sinus tachycardia. NOTE. Agonal respiratory rate indicates slow, shallow breathing pattern. Obtunded indicates conscious but moaning response only. Pepper indicates use of capsicum spray.

${ }^{*}$ Female.

was available for $13(72 \%)$ cases. Also listed in Table 2 is the use by law enforcement of the choke hold, taser device, or capsicum spray as either observed or reported to paramedics or noted in Coroner's reports. Listed in Table 3 are the results of postmortem comprehensive toxicological analysis and specific autopsy findings. All victims struggled with law enforcement personnel before being restrained and all had superficial abrasions and contusions of the body, including the head. Without exception, all cardiopulmonary arrests where unanticipated and preceded by a short period (estimates 5 minutes or less) during which the victim ceased in struggling against restraints and developed a labored or shallow breathing pattern. Table 4 lists factors that have been identified as associated with death from excited delirium when restrained with correlation to the findings of this case series. ${ }^{3,5}$ 5, 6, 9, 14, 15 Chronic diseases were considered to be present if identified by autopsy or known by history and are noted in Table 3. Patient number 17 in Tables 2 and 3, listed as having evidence of an old cerebral contusion was not considered to have chronic disease present. A BMI greater than 29 (midrange of preobese range) was considered as evidence of obesity. Recent literature has described the importance of severe meta-

TABLE 3. Autopsy Findings

\begin{tabular}{rcccc}
\hline Patient & Cocaine & Amphetamine & Other Drug & Anatomic Findings \\
\hline 1 & Yes & No & Ethanol & Mild coronary artery disease \\
2 & Yes & No & & Myocarditis/cardiomegaly \\
3 & Yes & No & & Fibrotic heart \\
4 & No & Yes & Ethanol & \\
5 & Yes & Yes & & Right ventricular hypertrophy \\
6 & No & No & & \\
7 & Yes & Yes & Ethanol & \\
8 & No & Yes & Marijuana & Fibrotic heart/fatty liver \\
9 & Yes & No & Ethanol \\
10 & No & No & & Cardiomegaly/fatty liver \\
11 & Yes & Yes & \\
12 & No & No & Phencycl & Left ventricular hypertrophy \\
$13^{\star}$ & Yes & No & Myocardial hypertrophy \\
14 & No & Yes & Cardiomegaly \\
15 & No & Yes & Ethanol & Old cerebral contusion \\
16 & Yes & No & & \\
17 & Yes & No & & \\
18 & No & No & & \\
\hline
\end{tabular}

${ }^{*}$ Female. 
TABLE 4. Potential Factors Associated With Death While Hobble Restrained for Excited Delirium

\begin{tabular}{|c|c|c|}
\hline Factor & $\begin{array}{l}\% \text { Factor } \\
\text { Present }\end{array}$ & $\begin{array}{c}\% \text { Factor } \\
\text { Absent }\end{array}$ \\
\hline Excited delirium & $100 \%$ & 0 \\
\hline Hobble restraint & $100 \%$ & 0 \\
\hline Prone position & $100 \%$ & 0 \\
\hline $\begin{array}{l}\text { Forceful struggle against } \\
\text { restraint }\end{array}$ & $100 \%$ & 0 \\
\hline $\begin{array}{l}\text { Stimulant drug use (positive } \\
\text { toxicology test) }\end{array}$ & $78 \%$ & $22 \%$ \\
\hline $\begin{array}{l}\text { Autopsy evidence of } \\
\text { chronic disease state }\end{array}$ & $56 \%$ & $44 \%$ \\
\hline $\begin{array}{c}\text { Obesity }(\text { BMI }>29 \\
\left.\mathrm{kg} / \text { meters }^{2}\right)\end{array}$ & $56 \%$ & $44 \%$ \\
\hline $\begin{array}{l}\text { Known chronic cocaine use } \\
\text { (by history) }\end{array}$ & $45 \%$ & * \\
\hline Capsicum spray & $33 \%$ & $67 \%$ \\
\hline Taser device & $28 \%$ & $72 \%$ \\
\hline $\begin{array}{c}\text { Primary cardiac (VF/NT) } \\
\text { dysrhythmia (\% of } \\
\text { confirmed rhythms) }\end{array}$ & $8 \%$ & $92 \%$ \\
\hline Neck compression & 0 & $100 \%$ \\
\hline \multicolumn{3}{|l|}{ Ethnic origin } \\
\hline African American & $33 \%$ & \\
\hline Hispanic & $33 \%$ & \\
\hline Caucasian & $33 \%$ & \\
\hline
\end{tabular}

Abbreviations: BMI, Body Mass Index; VF/VT, ventricular fibrillation/ ventricular tachycardia.

* \% without previous cocaine use uncertain because data from available historical sources.

bolic acidosis in association with restraint related sudden death. ${ }^{14}$ Although recognizing the contribution of this recent report, the presence of metabolic acidosis was not determined in this study. Reported though is observed struggle and fatigue against force from which it can be assumed there was a high potential for developing metabolic acidosis. Paramedics did not take patient temperatures in the field and because all victims arrived at receiving hospitals with ongoing resuscitation in progress, our data did not allow for valid determination of the presence or absence of hyperthermia.

\section{DISCUSSION}

A number of potential factors have been proposed as contributing to death while restrained for excited delirium (Table 4). ${ }^{3-6,15}, 16$ The favored factors include death attributable to stimulant drug toxicity (both acute and chronic effects), restraint asphyxia, and death secondary to underlying heart or other chronic disease. Of these factors, restraint asphyxia has been most controversial.

Restraint asphyxia is a term that expands the concept of positional asphyxia to include the process of subduing and restraining an individual. ${ }^{5}$ In the out-of-hospital setting, the process of restraining a victim of excited delirium usually involves "take down" where the individual is forced to the ground and the wrists bound behind the back. During this phase there is struggle by the individual with the potential for compression and restriction of the chest by placement of pressure (usually a knee or hand) on the back of the thorax with the individual in prone position while being subdued and initially restrained. After the "take down" phase, the individual may be further restrained into a hobbled, prone position. ${ }^{5}$ The entire process of subduing and restraining an uncooperative individual may have high risk for causing ventilation compromise.

All sudden death and the 196 surviving excited delirium victims in our population were restrained using some form of hobble restraint. Earlier in the study, victim's 4 extremities were usually tightly bound behind the back and after mid-1995 the extremities were more loosely bound. Other than the variation in tightness of binding, hobble-type techniques were exclusively used in the subduing of victims of excited delirium. Current evidence for an association of mechanical asphyxia from hobble restraints in the circumstance of excited delirium is based on observational autopsy reports. ${ }^{1-4}$ The concept has been questioned by demonstration in healthy, exercised volunteers that the hobble restraint position results in a significant decrease in both static and dynamic pulmonary function measurements but no hypoxia or hypercapnia related to restraint position..$^{9,}{ }^{10}$ Rather than an association with a specific restraint procedure and sudden death, our data and current literature can only be said to indicate an association for risk of sudden death with excited delirium that requires physical restraints to subdue an individual.

In our study population, all of the sudden death victims and $89 \%$ (155/174 for whom data were available) of those who did not suffer sudden death were restrained in a prone position. The data presented do not support or refute the prone position while hobble restrained as independently associated with sudden death in the setting of excited delirium.

Two of the sudden death victims were free of toxicological evidence of drugs and without autopsy evidence of cardiac or other natural disease. The 2 did have other potential risk factors including both having a BMI that placed them in the obese range and one subjected to capsicum spray. In none of the cases in this series was there an absence of all suspected potential risk factors for sudden death. Conversely, for other than excited delirium requiring restraint with struggle during restraint there were no risk factors found present in every case. Although there was struggle in each case reported in this series there was no evidence that head or other injury contributed to the sudden deaths.

Obviously, underlying heart disease is a potential risk for sudden death when considering the physical stress of excited delirium and struggle against restraint. Although 13 patients with initial cardiac rhythm description does not allow for statistically significant conclusions, our data did not indicate that cardiac arrest was a predominate factor associated with sudden death while hobble restrained for excited delirium. The initial cardiac rhythm was documented and confirmed in 13 of 18 patients (72\%). None of the victims were found initially to be in ventricular fibrillation, and only one (8\% of confirmed) was in ventricular tachycardia. Recent literature reports that $28 \%$ to $38 \%$ of out-of-hospital primary cardiac arrests present with the rhythm of ventricular fibrillation or ventricular tachycardia. ${ }^{17-20}$ When considering cardiac arrest actually witnessed by EMS personnel, there is a reported wide variation of $24 \%$ to $77 \%$ for ventricular fibrillation as the initial cardiac arrest rhythm..$^{21,22}$ If primary cardiac arrest were strongly associ- 
ated with sudden death while hobble restrained for excited delirium, it would be expected that more victims would have presented with ventricular fibrillation or ventricular tachycardia. It is acknowledged that because of delay in determination of initial rhythm because of the time necessary to release restraints for initiation of resuscitation, some victims could have had deterioration of ventricular fibrillation to asystole.

Evidence for stimulant drug use was present in $78 \%$ of the victims. None of the victims were noted by history or comprehensive postmortem toxicological analysis to have been taking phenothiazines or other drug classes commonly associated with a central neurologic homeostatic imbalance such as neuroleptic malignant syndrome. Obesity has also been considered an associated factor and only $44 \%$ of the arrest victims had a BMI in the normal to near normal range (20 to $29 \mathrm{Kg} / \mathrm{m}^{2}$ ). Ethnic origin was evenly distributed among victims. There was low association for capsicum spray and the Taser device, which were used in $33 \%$ and $28 \%$ of cases.

A limitation of this report is that the data collected did not allow for reliable assessment for the presence of hyperthermia as a potential factor for sudden death. Hyperthermia is important when considering factors associated with sudden death with restrained excited delirium. ${ }^{15,}{ }^{23}$ Karch and others have noted that those who die from restrained excited delirium are invariably hyperthermic. Hyperthermia in this setting has been reported to occur from neurochemical abnormalities in which there are fewer $D_{2}$ receptors in the hypothalamus that oppose $\mathrm{D}_{1}$ mediated temperature increases. ${ }^{15}, 23$ Karch further describes that changes in the number and distribution of opiate receptors within the amygdala induced by cocaine may account for the psychotic symptoms and agitation seen in excited delirium associated with cocaine use. It is clear that hyperthermia found when victims of excited delirium are encountered must be rapidly recognized and addressed when resuscitation is attempted.

Because this report is descriptive, causal inference cannot be made for the associated factors identified. Factors that were frequently associated with sudden death of restrained excited delirium victims included evidence for forceful struggle $(100 \%)$, stimulant drug use $(78 \%)$, established natural disease states $(56 \%)$, and obesity $(56 \%)$. Cessation of struggle against restraints and onset of shallow or labored breathing is a sign that was described in each of the sudden deaths. Conversely, ethnic origin was evenly distributed among the victims and therefore did not appear to be a contributing factor.

Because this report is a case series, the interpretation of data are limited to generally establishing factors that may be associated with sudden death while hobble restrained for excited delirium. Further study and observation is needed to more clearly define those factors that are causal to death while restrained for excited delirium.

Our data suggest that multiple factors can be associated with sudden death while restrained for excited delirium. These factors are not present in every case of sudden death, but instead probably act as cofactors that add to the risk of sudden death. Violent victims of excited delirium often must be restrained for the safety of the individual and the public. It should be recognized that such individuals are at high risk for sudden death, particularly those who are obese, under the influence of stimulant drugs, and have underlying medical disease. A sign of impending cardiopulmonary arrest while restrained for excited delirium is cessation of struggle against restraints and onset of shallow or labored breathing. Alternative restraint methods either physical or chemical and other techniques for control of victims of excited delirium should be explored and strongly considered.

\section{REFERENCES}

1. Reay DT, Flinger CL, Stilwell AD, et al: Positional asphyxia during law enforcement transport. Am J Forensic Med Pathol 1992; 13:90-97

2. Bell MD, Rao VJ, Wetli CV, et al: Positional asphyxiation in adults: A series of 30 cases from the Dade and Broward County Florida Medical Examiners Offices from 1982 to 1990. Am J Forensic Med Pathol 1992;13:185-192

3. O'Halloran RL, Lewman LV: Restraint asphyxiation in excited delirium. Am J Forensic Med Pathol 1993;14:289-295

4. Pollanen MS, Chiasson DA, Cairns JT, et al: Unexpected death related to restraint for excited delirium: A retrospective study of deaths in police custody and in the community. CMAJ 1998;158: 1603-1607

5. Reay DT: Death in custody. Clin Lab Med 1998;18:1-22

6. Ross DL: Factors associated with excited delirium deaths in police custody. Mod Pathol 1998;11:1127-37

7. Stratton SJ, Rogers C, Green K: Sudden death in individuals in hobble restraints during paramedic transport. Ann Emerg Med 1995;25:710-712

8. Reay DT, Howard JD, Flinger CL, et al: Effect of positional restraint on oxygen saturation and heart rate following exercise. Am J Forensic Med Pathol 1988;9:16-18

9. Chan TC, Vilke GM, Neuman T, et al: Restraint position and positional asphyxia. Ann Emerg Med 1997;30:578-86

10. Schmidt $P$, Snowden $T$ : The effects of positional restraint on heart rate and oxygen saturation. J Emerg Med 1999;17:777-82

11. Roeggla M, Wagner A, Muellner M, et al: Cardiorespiratory consequences to hobble restraint. Wien Klin Wochenschr 1997;109: 359-361

12. World Health Organization: Press Release WHO/46; 1997

13. Burke AP, Farb A, Tang A, et al: Fibromuscular dysplasia of small coronary arteries in fibrosis in the basilar ventricular septum in mitral valve prolapse. Am Heart J 1997;134:282-291

14. Hick JL, Smith SW, Lynch MT: Metabolic acidosis in restraintassociated cardiac arrest: a case series. Acad Emerg Med 1999;6: 239-43

15. Karch SB: Drug abusers who die during arrest or in custody. J Royal Soc Med 1999;92:110-113

16. Chan TC, Vilke GM, Neuman T: Reexamination of custody restraint position and positional asphyxia. Am J Forensic Med Pathol 1998;19:201-205

17. Stiell IG, Wells GA, Field BJ, et al: Improved out-of-hospital cardiac arrest survival through the inexpensive optimization of an existing defibrillation program: OPALS Study phase II. JAMA 1999; 281:1175-1181

18. Stratton S, Niemann JT: Effects of adding links to the chain of survival; for prehospital cardiac arrest: a contrast in outcomes in 1975 and 1995 at a single institution. Ann Emerg Med 1998;31:471477

19. Westal RE, Reissman S, Doering G: Out-of-hospital cardiac arrests: An 8-year New York City experience. Am J Emerg Med 1996;14:364-368

20. Isaacs E, Callahan ML: Ability of laypersons to estimate short time intervals in cardiac arrest. Ann Emerg Med 2000;35: 147-154

21. Gallagher EJ, Lombardi G, Gennis P: Cardiac arrest witnessed by prehospital personnel: Intersystem variation in initial rhythm as a basis for a proposed extension of the Utstein recommendations. Ann Emerg Med 1997;30:76-81

22. De Maio VJ, Stiell IG, Wells GA, et al: Cardiac arrest witnessed by emergency medical services personnel: Descriptive epidemiology, prodromal symptoms, and predictors of survival. OPALS study group. Ann Emerg Med 2000;35:138-46

23. Karch SB: Acute excited states are not caused by high blood concentration of cocaine. BMJ 1998;316:1171 